\title{
Levels of endothelial substances in patients with newly identified hypertension compared with healthy controls
}

\author{
Vladislav Biela, Jan Novak ${ }^{\mathrm{a}, \mathrm{b}}$, Veronika Rimalovac, Marie Tomandlovad ${ }^{\mathrm{d}}$, Josef Tomandld ${ }^{\mathrm{d}}$, Jiri Spac ${ }^{\mathrm{a}}$, Miroslav Soucek ${ }^{\mathrm{a}}$
}

Introduction. Endothelial dysfunction occurs at the very beginning of hypertension. The primary goal of our study was to determine plasmatic levels of multiple endothelial substances in otherwise healthy patients with primary hypertension and compare them to healthy individuals. Secondary goals were to determine the change in NOx levels after initiation of treatment and to compare the NOx levels in patients with established resistant hypertension.

Materials and Methods. 87 consecutive patients were enrolled. In the exploratory cohort of 22 healthy and 28 hypertensive individuals, plasmatic levels of big endotelin-1, asymmetric dimethylarginin, osteopontin, oxidized LDL, 3-nitro-L-tyrosine, growth/differentiation factor 15, intercellular adhesion molecule, vascular cell adhesion molecule, tumor necrosis factor- $\alpha$, vascular endothelial growth factor, interleukins $-1 \beta,-6$ and nitric oxide levels (NO, expressed as NOx) were determined. The remaining 27 individuals were used as a validation cohort. Ten patients with established resistant hypertension were enrolled from our Hypertension Clinic.

Results. There was a statistically significant difference in NOx levels between healthy controls and hypertensive patients/resistant hypertensive patients: $45.164 \mu \mathrm{mol} / \mathrm{L} \pm 48.627 \mathrm{vs} 17.763 \mu \mathrm{mol} / \mathrm{L} \pm 10.333(P=0.00004) / 14.36 \mu \mathrm{mol} / \mathrm{L}$ $\pm 7.194(P=0.00007)$.

Conclusion. We identified a decrease in total NOx plasmatic levels in otherwise healthy patients with primary hypertension that was more profound in patients with resistant hypertension. Plasmatic levels of other determined endothelial substances did not differ among the groups. However, due to the significant variability of plasmatic NOx levels even in healthy controls and many factors that affect it, we cannot recommend it to be used to assess endothelial function routinely.

Key words: hypertension, nitric oxide, plasma, endothelial dysfunction

Received: August 12, 2020; Revised: November 25, 2020; Accepted: December 8, 2020; Available online: January 12, 2021 https://doi.org/10.5507/bp.2020.062

(c) 2021 The Authors; https://creativecommons.org/licenses/by/4.0/

${ }^{a} 2^{\text {nd }}$ Department of Internal Medicine, St. Anne's University Hospital in Brno and Faculty of Medicine, Pekarska 53, Brno, 65691, Czech Republic

${ }^{b}$ Department of Physiology, Faculty of Medicine, Masaryk University, Kamenice 5, Brno, 62500, Czech Republic 'Center of Biostatistics, International Clinical Research Center of St. Anne's University Hospital, Pekarska 53, Brno, 65691, Czech Republic ${ }^{d}$ Department of Biochemistry, Faculty of Medicine, Masaryk University, Kamenice 5, Brno, 62500, Czech Republic Corresponding author: Vladislav Biel, e-mail: ladabiel@gmail.com

\section{INTRODUCTION}

Arterial hypertension is defined as a repeatedly measured office systolic $\geq 140 \mathrm{mmHg}$ and/or diastolic blood pressure $\geq 90 \mathrm{mmHg}\left(\right.$ ref. $\left.^{1}\right)$. Arterial hypertension is considered a major preventable cause of other cardiovascular diseases and blood pressure (BP) lowering has repeatedly been shown in multiple randomized controlled trials to decrease cardiovascular risk ${ }^{1,2}$. According to the World Health Organization data, there were more than one billion people worldwide (about $22 \%$ of the world's population) suffering from high BP in 2014 and alarming is that arterial hypertension occurrence is increasingly found in younger age groups ${ }^{3,4}$. Despite the significant progress made in our understanding of arterial hypertension pathophysiology, aside from secondary causes of arterial hypertension, in more than $90 \%$ of all cases of arterial hypertension, the primary insult leading to increase in BP is still not easily identifiable and even in a single patient, arterial hypertension pathophysiology is highly complex and multifactorial ${ }^{1,5}$.

One of the factors contributing to the maintenance of $\mathrm{BP}$ is the proper function of the endothelium and accordingly, endothelial dysfunction (ED) is one of the factors contributing to $\mathrm{BP}$ increase ${ }^{5}$. ED, as a term, is generally used to describe the imbalance among the relaxing and constricting factors produced by the endothelium. However, the endothelium also has other functions as it modulates the function of thrombocytes and leukocytes by producing a range of cytokines and interleukins (thus affecting inflammation and blood clotting), and it affects angiogenesis, reactive oxygen species and LDL oxidation. Moreover, other extrinsic factors that are also hypertension-related risk factors, such as obesity, smoking and diabetes mellitus, are known to lead to ED, which makes it further challenging to distinguish ED caused either by hypertension itself or its risk factors ${ }^{5}$.

ED can be determined by several methods. In practice, 
flow mediated dilation (FMD) is most often used. This is based on the change in artery diameter after an episode of ischemia. The method has a number of limitations, especially complex preparation of subjects with strict regimens, relatively low accuracy (small ratio of changes in arterial diameter and vascular probe resolution) and lack of observational studies with established FMD reference values for different subpopulations, e.g. age, BMI, gender, smoking, etc. $\left(\right.$ ref. $\left.^{6}\right)$. Another possible method is to determine the plasma levels of endothelial substances. Knowing the right biochemical marker would facilitate therapeutic intervention at the start of hypertension (i.e. still in the phase with normal BP). The main goal of this study was to identify an endothelial substance with such a biomarker potential.

\section{METHODS}

\section{Subjects}

This was a bicentric study. The total of 77 consecutive individuals were sent by their general practitioners and were enrolled at the Hypertension Clinic of the $2^{\text {nd }}$ Department of Internal Medicine, St. Anne's University Hospital in Brno, Brno, Czech Republic and at the Department of Internal Medicine, Boskovice Hospital, Boskovice, Czech Republic. The study was approved by the Ethics committee of St. Anne's University hospital and the Ethics committee of Boskovice hospital in accordance with the latest Declaration of Helsinki. Before the enrollment, all participants provided written informed consent and they completed a questionnaire about their lifestyle, especially dietary habits, including alcohol use. Inclusion criteria were office BP $<140 / 90 \mathrm{mmHg}$ for the control group and office BP $\geq 140 / 90 \mathrm{mmHg}$ for the hypertensive group. The result was confirmed by $24 \mathrm{~h}$ ambulatory blood pressure monitoring (24-ABPM, device IEM Mobil-o-graph, software Socrates I3) to exclude the white coat syndrome. Exclusion criteria were: age below 18 and over 60 years, body mass index above $35 \mathrm{~kg} / \mathrm{m}^{2}$, positive smoking history, daily intake of fruits and vegetables under $200 \mathrm{~g}$ each, daily acohol consumption above 2 drinks ( 1 drink defined as $8 \mathrm{~g}$ of pure alcohol), anamnesis or the presence of any treated or untreated internal disease (such as ischemic heart disease, myocardial infarction, type 2 diabetes mellitus, chronic kidney disease, hyperuricemia, dyslipidemia, bronchial asthma, chronic obstructive pulmonary disease, hypo- or hyperthyreosis, rheumatic arthritis, Crohn's disease, ulcerative colitis etc.) and any previous or currently ongoing malignancies. The participants were drug naive. We did not exclude secondary hypertension for economic reasons, however, all the subjects in the hypertension subgroup had to lack the general features of secondary hypertension listed in the 2018 ESC / ESH Guidelines for the Management of Arterial Hypertension (e.g. hypokalemia etc) (ref. ${ }^{7}$ ).

Another 10 patients with estabilished resistant hypertension were enrolled at the Hypertension Clinic of the $2^{\text {nd }}$ Department of Internal Medicine, St. Anne's University in Brno, Czech Republic. Resistant hypertension was defined as a condition in which, despite treatment with triple combinations of antihypertensives including diuretics, BP values below 140/90 mm $\mathrm{Hg}$ were not achieved.

Generally, the enrollment was focused on otherwise healthy individuals in whom only normal or increased BP was identified. All enrolled individuals underwent office $\mathrm{BP}$ measurement according to the ESC/ESH Guidelines for the management of arterial hypertension from 2018 - briefly: after $10 \mathrm{~min}$ at rest, the upper non-dominant limb, cuff placed at the level of the heart, the resultant value was an average of the second and the third measurement. Based on the obtained BP values, participants were divided into healthy controls (22 individuals, including 10 females), hypertensive subjects ( 55 individuals, including 9 females). The third group was enrolled separately and consisted of individuals with known resistant hypertension $(n=10)$. For the screening purposes (i.e. for the identification of potential endothelial substances altered in the initial phases of hypertension), a group of 22 controls and 28 hypertensive patients were selected as the exploratory cohort. For validation purposes, the rest of the cohort were hypertensive patients who served as a validation cohort only for those substances that were identified in the exploratory cohort.

\section{Blood sampling}

In standard routine blood sampling, basic laboratory tests were performed in an accredited laboratory. The tests included plasma levels of sodium, potassium, chloride, ALT, AST, GGT, ALP, urea, creatinine, uric acid, thyroid stimulating hormone, total cholesterol, lowdensity lipoproteins (LDL), high-density lipoproteins (HDL) and triglycerides (sampling was not timed according to the phase of the menstrual cycle in the women). For the purposes of the study, two more blood collection tubes (containing potassium EDTA) were obtained. The samples were immediately centrifuged (2000 rpm for 5 minutes at $4^{\circ} \mathrm{C}$ ). The separated plasma was aliquoted and stored subsequently at $-70{ }^{\circ} \mathrm{C}$ until analysis.

\section{Initiation of antihypertensive treatment}

After completion of the initial examination (including blood sampling), antihypertensive therapy was initiated with a combination of a perindopril and amlodipine. In case of adverse reactions to ACE inhibitors (especially dry cough), perindopril was replaced by telmisartan.

\section{Echocardiography}

Echocardiography was performed on GE Medical Vivid S6. Basic morphological and functional parameters were obtained as follows: diameter of the left ventricle in systole (LVs) and diastole (LVd), interventricular septum thickness (IVS), posterior wall thickness (PW), left atrial diameter (LA) and ejection fraction of the left ventricle (LV EF).

\section{ELISA measurement of endothelial substances}

Levels of endothelial substances were determined in the Department of Biochemistry, Faculty of Medicine, Masaryk University, Brno, Czech Republic. Levels of big- 
endothelin-1 (bigET-1, Biomedica, Austria), asymmetric dimethyl arginine (ADMA, Cloud-Clone Corp., USA), osteopontin (OPN, R\&D Systems, USA), oxidized LDL (oxLDL, Cusabio, USA), were measured using enzymelinked immuno sorbent assays according to manufacturer's instructions. Plasma concentrations of growth differentiation factor-15 (GDF15) and endothelial adhesion molecules (ICAM, VCAM) were measured using the Human Cardiovascular Disease Panel 2 Magnetic Bead Kit (EMD Millipore, USA). Plasma concentrations of tumor necrosis factor alpha $(\mathrm{TNF} \alpha)$, vascular endothelial growth factor (VEGF) and two interleukins (specifically IL-1 $\beta$ and IL-6) were measured using the Human High Sensitivity Cytokine Base Kit A (R\&D Systems, USA). Plasmatic concentrations of nitric oxide (NO) were determined using colorimetric assay kit based on the Griess reaction (R\&D Systems, USA) and are expressed it as
$\mathrm{NOx}$ (i.e. sum of $\mathrm{NO}_{2}^{-}$and $\mathrm{NO}_{3}^{-}$plasmatic concentrations).

\section{Statistical analysis}

The differences between groups were assessed by oneway ANOVA or by Kruskal-Wallis test, if the normality condition was not met. Shapiro-Wilk test was used to test normality. Post hoc comparisons were performed using Dunn's test. A value of $\alpha$ equal to or below 0.05 was considered statistically significant. Multiplicity correction was performed using the Benjamini-Hochberg method. To examine correlations among variables, the Pearson correlation coefficient was used. Data are expressed as means \pm standard deviations if the normality condition was met, otherwise as the median and interquartile range (IQR). Statistical analysis was performed using software $\mathrm{R}$ (version 3.6.0) and RStudio (version 1.2.1335).

Table 1. Basic demographic data for the study groups.

\begin{tabular}{|c|c|c|c|}
\hline & Parameter & Control group & Hypertension group \\
\hline \multirow[t]{3}{*}{ Basics } & No. of individuals & 22 & 55 \\
\hline & Age [years] & $32.45 \pm 7.64$ & $36.61 \pm 11.53$ \\
\hline & BMI $\left[\mathrm{kg} / \mathrm{m}^{2}\right]$ & $29.64 \pm 5.92$ & $29.02 \pm 4.12$ \\
\hline \multirow[t]{8}{*}{ Blood pressure } & BP syst in office & $125.00 \pm 3.46$ & $155.53 \pm 16.37$ \\
\hline & BP diast in office & $79.33 \pm 2.52$ & $100.37 \pm 14.45$ \\
\hline & 24h ABPM total syst & $117.00 \pm 7.81$ & $140.81 \pm 9.00$ \\
\hline & 24h ABPM total diast & $69.33 \pm 11.02$ & $86.58 \pm 7.90$ \\
\hline & 24h ABPM day syst & $120.00 \pm 7.81$ & $146.21 \pm 11.02$ \\
\hline & 24h ABPM day diast & $71.67 \pm 11.59$ & $91.04 \pm 8.72$ \\
\hline & 24h ABPM night syst & $108.67 \pm 8.51$ & $128.83 \pm 10.49$ \\
\hline & 24h ABPM night diast & $66.33 \pm 13.58$ & $75.42 \pm 10.46$ \\
\hline \multirow[t]{18}{*}{ Clinical chemistry } & Natrium $[\mathrm{mmol} / \mathrm{L}]$ & $140.50 \pm 1.00$ & $137.78 \pm 16.31$ \\
\hline & Kalium [mmol/L] & $4.20 \pm 0.41$ & $4.30 \pm 0.34$ \\
\hline & Chloride $[\mathrm{mmol} / \mathrm{L}]$ & $104.50 \pm 2.38$ & $102.97 \pm 2.67$ \\
\hline & Urea $[\mathrm{mmol} / \mathrm{L}]$ & $4.58 \pm 1.02$ & $5.03 \pm 0.76$ \\
\hline & Creatinine $[\mu \mathrm{mol} / \mathrm{L}]$ & $79.25 \pm 13.07$ & $86.26 \pm 9.53$ \\
\hline & TSH $[\mathrm{mIU} / \mathrm{L}]$ & $1.60 \pm 1.15$ & $1.85 \pm 0.79$ \\
\hline & fT4 [pmol/L] & $12.54 \pm 2.27$ & $13.15 \pm 1.97$ \\
\hline & Bilirubin $[\mu \mathrm{mol} / \mathrm{L}]$ & $8.55 \pm 3.65$ & $15.84 \pm 16.25$ \\
\hline & ALT $[\mu \mathrm{kat} / \mathrm{L}]$ & $0.56 \pm 0.10$ & $0.63 \pm 0.29$ \\
\hline & AST $[\mu \mathrm{kat} / \mathrm{L}]$ & $0.47 \pm 0.03$ & $0.39 \pm 0.09$ \\
\hline & GGT $[\mu \mathrm{kat} / \mathrm{L}]$ & $0.50 \pm 0.20$ & $0.74 \pm 0.38$ \\
\hline & $\operatorname{ALP}[\mu \mathrm{kat} / \mathrm{L}]$ & $1.24 \pm 0.18$ & $1.26 \pm 0.48$ \\
\hline & Uric acid $[\mu \mathrm{mol} / \mathrm{L}]$ & $338.00 \pm 77.90$ & $299.71 \pm 111.51$ \\
\hline & Total cholesterol $[\mathrm{mmol} / \mathrm{L}]$ & $4.60 \pm 0.42$ & $4.64 \pm 0.61$ \\
\hline & Triacylglycerols [mmol/L] & $2.91 \pm 1.12$ & $1.45 \pm 0.50$ \\
\hline & $\mathrm{LDL}[\mathrm{mmol} / \mathrm{L}]$ & $2.27 \pm 0.22$ & $2.72 \pm 0.86$ \\
\hline & $\mathrm{HDL}[\mathrm{mmol} / \mathrm{L}]$ & $1.30 \pm 0.64$ & $1.47 \pm 0.38$ \\
\hline & Glycemia $[\mathrm{mmol} / \mathrm{L}]$ & $5.22 \pm 0.40$ & $5.25 \pm 0.37$ \\
\hline \multirow[t]{5}{*}{ Echocardiography } & IVSd [mm] & $9.50 \pm 0.58$ & $11.24 \pm 2.13$ \\
\hline & $\mathrm{LVd}[\mathrm{mm}]$ & $48.50 \pm 10.28$ & $47.90 \pm 3.64$ \\
\hline & LVs $[\mathrm{mm}]$ & $30.75 \pm 5.38$ & $30.21 \pm 4.99$ \\
\hline & PWd [mm] & $8.50 \pm 1.92$ & $10.11 \pm 1.67$ \\
\hline & $\mathrm{LA}[\mathrm{mm}]$ & $37.25 \pm 6.75$ & $37.17 \pm 4.18$ \\
\hline
\end{tabular}

BP blood pressure, 24h ABPM 24h ambulatory blood pressure monitoring, diast diastolic, syst systolic, IVSd interventricular septum diastolic size, LA left atrium systolic size, LVd left ventricle diastolic size, LVs left ventricle systolic size, PWd left ventricle posterior wall diastolic size, LV EF, left ventricle ejection fraction. 


\section{RESULTS}

\section{Study groups characteristics}

The descriptive statistics for each subgroup is provided in Table 1 including age, BP, BMI, results for the basic laboratory examination and echocardiography. Between group differences were examined using the Mann-Whitney test. Study groups did not differ significantly in these parameters, except for the values of $\mathrm{BP}$ and the number of females.

\section{Plasmatic concentrations of endothelial substances}

There were no statistically significant differences between patients with newly identified hypertension and controls in plasmatic concentrations of bigET-1, ADMA, OPN, oxLDL, 3NT, GDF15, ICAM, VCAM, TNF- $\alpha$, VEGF, IL-1 $\beta$ and IL-6 (plasmatic concentration of bigET-1, oxLDL, GDF-15, VCAM-1 and IL-1 $\beta$ were only insignificantly higher in patients with newly identified hypertension, summarized in Table 2).

Plasmatic concentrations of nitric oxide expressed as NOx were significantly different between healthy controls, newly identified hypertensive patients in the exploratory cohort and resistant hypertensive patients: 29.81 (24.633 - 40.523), 16.77 (10.233 - 22.402) and 13.09 (9.193 18.927) $\mu \mathrm{mol} / \mathrm{L}$, respectively, $P=0.00005$, Kruskal-Wallis test statistic was 24.978. A post hoc comparison showed significant differences between healthy controls and all hypertensive patients, i.e. exploratory and validation cohort together $(P=0.00004)$ and between groups of controls and resistant hypertensive patients $(P=0.00007)$. A significant difference between groups was also found between healthy controls, all hypertensive patients and patients with resistant hypertension: 29.81 (24.633 - 40.523), 21.9 (15.555 - 29) and 13.09 (9.193 - 18.927) $\mu \mathrm{mol} / \mathrm{L}$, respectively, $P=0.00014$, Kruskal-Wallis test statistic 21.427 . A post hoc comparison showed significant difference between healthy controls and all hypertensive patients, i $(P=0.00081)$, between controls and patients with resistant hypertension $(P=0.00004)$ and between groups of all hypertensive patients and patients with resistant hypertension $(P=0.02259)$.

\section{Correlation analysis of plasmatic concentrations of nitric oxide with blood pressure values}

No statistically significant correlations of NOx plasmatic concentrations with $\mathrm{BP}$ values (both office $\mathrm{BP}$ and 24h ABPM values) were found (Table 3 ).

\section{Plasmatic concentration of NOx after initiation of hypertension treatment}

Eleven patients with newly diagnosed hypertension underwent a clinical follow-up 6-12 months after initiation of treatment, which was verified by ABPM and plasmatic NOx levels were then determined. Paired Wilcoxon signed-rank test showed no significant difference in plasma NOx levels after initiation of antihypertensive therapy compared to pre-treatment values $(23.62 \pm 17.25 \mu \mathrm{mol}$ vs $21.54 \pm 8.18 \mu \mathrm{mol}, P=0.4648)$. Additionally, correlation between NOx levels and BP values for 7 pre-treatment and

Table 2. Plasmatic levels of determined substances.

\begin{tabular}{|c|c|c|c|c|c|c|c|c|c|c|c|}
\hline \multirow{2}{*}{$\begin{array}{l}\text { Substance } \\
\text { No. of patients }\end{array}$} & \multicolumn{2}{|r|}{ Control group } & \multicolumn{2}{|c|}{ Hypertension group } & \multicolumn{2}{|c|}{$\begin{array}{l}\text { Resistant hyperten- } \\
\text { sion group }\end{array}$} & \multicolumn{2}{|c|}{$\begin{array}{l}\text { Group compari- } \\
\text { son }\end{array}$} & \multicolumn{3}{|c|}{ Post-hoc comparison - adj. $P$} \\
\hline & $\mathrm{n}$ & Summary & $\mathrm{n}$ & Summary & $\mathrm{n}$ & Summary & $\begin{array}{c}\text { Test } \\
\text { statistic }\end{array}$ & $\begin{array}{c}\text { Adjusted } \\
P\end{array}$ & $\mathrm{C}-\mathrm{H}$ & C-R & $\mathrm{H}-\mathrm{R}$ \\
\hline $\begin{array}{l}\text { NOx }(\mu \mathrm{mol} / \mathrm{L}) \text { in } \\
\text { exploratory cohort* }\end{array}$ & 22 & $\begin{array}{c}29.81 \\
(24.633-40.523)\end{array}$ & 28 & $\begin{array}{c}16.77 \\
(10.233-22.402)\end{array}$ & 10 & $\begin{array}{c}13.09 \\
(9.193-18.927)\end{array}$ & 24.978 & 0.00005 & 0.00004 & 0.00007 & 0.39262 \\
\hline $\begin{array}{l}\text { NOx }(\mu \mathrm{mol} / \mathrm{L}) \text { in all } \\
\text { individuals* }\end{array}$ & 22 & $\begin{array}{c}29.81 \\
(24.633-40.523)\end{array}$ & 55 & $\begin{array}{c}21.9 \\
(15.555-29)\end{array}$ & 10 & $\begin{array}{c}13.09 \\
(9.193-18.927)\end{array}$ & 21.427 & 0.00014 & 0.00081 & 0.00004 & 0.02259 \\
\hline bigET-1 $(\mathrm{pmol} / \mathrm{L})^{*}$ & 18 & $\begin{array}{c}0.182 \\
(0.141-0.309)\end{array}$ & 27 & $\begin{array}{c}0.21 \\
(0.13-0.416)\end{array}$ & 10 & $\begin{array}{c}0.23 \\
(0.19-0.302)\end{array}$ & 0.66 & 0.78803 & - & - & - \\
\hline $\operatorname{ADMA}(\mathrm{ng} / \mathrm{mL})$ & 4 & $14.808 \pm 1.84$ & 18 & $14.261 \pm 2.823$ & 10 & $15.184 \pm 3.455$ & 0.324 & 0.78803 & $\therefore$ & - & - \\
\hline $\mathrm{OPN}(\mathrm{ng} / \mathrm{mL})$ & 18 & $60.851 \pm 21.808$ & 28 & $60.222 \pm 16.828$ & 10 & $51.079 \pm 11.39$ & 1.142 & 0.78803 & - & - & - \\
\hline oxLDL $(\mathrm{U} / \mathrm{mL})^{*}$ & 18 & $\begin{array}{c}11.125 \\
(10.232-15.155)\end{array}$ & 28 & $\begin{array}{c}12.95 \\
(11.053-14.835)\end{array}$ & 10 & $\begin{array}{c}10.570 \\
(9.915-11.175)\end{array}$ & 5.529 & 0.27305 & - & - & - \\
\hline GDF-15 (pg/mL)* & 14 & $\begin{array}{c}288.1 \\
(299.207-320.043)\end{array}$ & 10 & $\begin{array}{c}258.06 \\
(225.188-341.397)\end{array}$ & - & - & 0.278 & 0.78803 & - & - & - \\
\hline $\mathrm{ICAM}-1(\mathrm{ng} / \mathrm{mL})$ & 14 & $71.353 \pm 16.513$ & 11 & $65.314 \pm 27.773$ & - & - & 0.459 & 0.78803 & - & - & - \\
\hline VCAM-1 (ng/mL) & 14 & $473.351 \pm 119.856$ & 10 & $488.177 \pm 117.939$ & - & - & 0.09 & 0.78803 & - & - & - \\
\hline $\mathrm{TNF}-\alpha(\mathrm{pg} / \mathrm{mL})$ & 14 & $3.681 \pm 1.625$ & 10 & $3.205 \pm 1.559$ & - & - & 0.517 & 0.78803 & - & - & - \\
\hline $\operatorname{VEGF}(\mathrm{pg} / \mathrm{mL})^{*}$ & 14 & $\begin{array}{c}4.04 \\
(0.28-8.295) \\
\end{array}$ & 10 & $\begin{array}{c}2.64 \\
(0.28-6.898)\end{array}$ & - & - & 0.293 & 0.78803 & - & - & - \\
\hline $\mathrm{IL}-1 \beta(\mathrm{pg} / \mathrm{mL})$ & 14 & $0.241 \pm 0.096$ & 10 & $0.254 \pm 0.13$ & - & - & 0.074 & 0.78803 & - & $\therefore$ & - \\
\hline IL-6 $(\mathrm{pg} / \mathrm{mL})^{*}$ & 14 & $\begin{array}{c}0.73 \\
(0.655-0.898)\end{array}$ & 10 & $\begin{array}{c}0.74 \\
(0.58-0.908)\end{array}$ & - & - & 0.086 & 0.78803 & - & - & - \\
\hline
\end{tabular}

bigET-1 big endothelin-1, ADMA asymmetric dimethyl arginine, OPN osteopontin, oxLDL oxidized LDL, GDF15 growth differentiation factor-15, ICAM intercellular adhesion molecule, VCAM vascular cell adhesion molecule, TNF $\alpha$ tumor necrosis factor alpha, VEGF vascular endothelial growth factor, IL-1 $\beta$, IL-6 interleukins, C control group, H hypertension group, R resistant hypertension group, * groups compared by the KruskalWallis test (as the normality condition was not met), otherwise by ANOVA, multiplicity correction by Benjamini-Hochberg method, significance level $\alpha=0.05$. Data are expressed as mean \pm standard deviation when the normality condition is met, otherwise expressed as median (IQR). 
Table 3. Correlations of NOx with blood pressure in hypertensive individuals.

\begin{tabular}{lcc}
\hline Parameter & $\begin{array}{c}\text { Pearson } \\
\text { correlation }\end{array}$ & $P$ \\
\hline BPs in office (mmHg) & 0.129 & 0.496 \\
BPd in office (mmHg) & 0.273 & 0.144 \\
HF in office (beats per min) & -0.017 & 0.931 \\
24h ABPM total syst (mmHg) & -0.165 & 0.42 \\
24h ABPM total diast (mmHg) & -0.193 & 0.345 \\
24h ABPM total HF (beats per min) & -0.178 & 0.405 \\
24h ABPM day syst (mmHg) & -0.178 & 0.406 \\
24h ABPM day diast (mmHg) & -0.147 & 0.494 \\
24h ABPM day HF (beats per min) & -0.207 & 0.343 \\
24h ABPM night syst (mmHg) & -0.053 & 0.807 \\
24h ABPM night diast (mmHg) & -0.132 & 0.537 \\
24h ABPM night HF (beats per min) & -0.315 & 0.143 \\
\hline
\end{tabular}

24h ABPM 24h ambulatory blood pressure measurement, BPd diastolic blood pressure, BPs systolic blood pressure, diast diastolic, HF heart frequency, syst systolic

5 post-treatment individuals was examined. No statistically significant correlations were found (Table 4).

\section{DISCUSSION}

The primary aim of our study was to determine the plasmatic levels of multiple endothelial and immunological substances in otherwise healthy patients with primary hypertension and compare these levels to both healthy controls and patients with resistant hypertension. We determined plasmatic levels of many substances (see above) that are known to be involved in maintaining endothelial function in the exploratory cohort of 50 patients. From all measured substances, only levels of NO (determined as NOx) were shown to be statistically significantly decreased in patients with newly identified hypertension. This decrease was further validated in the larger validation cohort of patients with primary hypertension and was also profound in patients with resistant hypertension.

Production of plasmatic NO is primary maintained by endothelial NO synthase (eNOS), which metabolizes
L-arginine to NO, which is very potent endothelial vasodilator $^{5}$. NOS is an enzyme with highly complex activity regulation that is affected by the concentration of many substances (acetylcholine, histamine, thrombin, serotonin, ADP, bradykinin, VEGF, substance P, ATP, isoproterenol, insulin, apelin, omentin, visfatin, leptin among others) and both endogenous (e.g. the inhibitory hypofunctional mutation G894T predisposing to hypertension ${ }^{8}$ ) and exogenous factors (e.g. physical activity, overweight, smoking and dietary habits, especially fruit and vegetable intake as a source of arginin, which can directly increase plasmatic levels of NO) ( ref. $^{9-15}$ ).

The large number of factors affecting NOS acitivity leads to high variability in NO plasmatic levels. Even in the group of healthy controls with normal BP values, the plasmatic NOx levels varied widely between 16.3 and 245 $\mu \mathrm{mol} / \mathrm{L}$. This may partially explain the lack of association of NO levels with other variables (except BP) observed in our study and also contributes to differences and heterogeneity of studies described further.

Importance of NO in the hypertension development has repeatedly been demonstrated in animal experiments in whose NOS inactivation (pharmacological or by gene silencing) lead to an increase in mean arterial pressure of $30-50 \mathrm{mmHg}\left(\right.$ ref. $\left.^{16}\right)$. Some studies focusing on NO metabolism and hypertension have already been performed and their results are generally consistent with our findings. Node et al. published a relatively large study in the Hypertension journal in 1997, showing that plasmatic NO levels are inversely proportional to BP levels ${ }^{17}$. Perticone et al. showed a direct correlation between BP and ADMA levels in patients with metabolic syndrome ${ }^{18}$. ADMA was also determined in our exploratory cohort, and there was no statistically significant difference between controls and hypertensive patients - the possible explanation is that we excluded individuals with metabolic syndrome and enrolled only otherwise healthy normal-weight individuals, which may suggest that ADMA levels changes are induced in hypertensive individuals rather by metabolic syndrome than hypertension itself. In another studies, Ceconi et al. showed an increase in NOx level and a decrease in endothelin-1 and TNF- $\alpha$ plasmatic concentrations after 1 year of treatment with perindopril ${ }^{19}$, similarly, Ito et al. demonstrated that therapy with perindopril and losartan

Table 4. Pre-treatment and post-treatment correlations of NOx with blood pressure.

\begin{tabular}{|c|c|c|c|c|}
\hline & \multirow[t]{2}{*}{ Parameter } & \multirow[t]{2}{*}{ Value } & \multicolumn{2}{|c|}{ Correlation with corresponding NOx levels } \\
\hline & & & Pearson correlation & $P$ \\
\hline & Number of patients & 11 & & \\
\hline \multirow{3}{*}{$\stackrel{o}{\text { Z }}^{\text {Z }}$} & Average pre-treatment NOx levels $(\mu \mathrm{mol})$ & $21.54 \pm 8.18$ & -0.172825 & 0.711 \\
\hline & NOx levels after initiation of therapy ( $\mu \mathrm{mol})$ & $23.62 \pm 17.25$ & 0.6296229 & 0.255 \\
\hline & $P$-value & 0.4648 & -0.410874 & 0.3598 \\
\hline \multirow{4}{*}{$\stackrel{\rho}{\infty}$} & Average preatreatment $24 \mathrm{~h}$ ABPM BPs (mmHg) & $148.43 \pm 11.15$ & -0.5189602 & 0.3702 \\
\hline & Average posttreatment 24h ABPM BPs (mmHg) & $125.60 \pm 4.67$ & & \\
\hline & Average pretreatment 24h ABPM BPd $(\mathrm{mmHg})$ & $91.57 \pm 9.88$ & & \\
\hline & Average posttreatment $24 \mathrm{~h} \mathrm{ABPM} \mathrm{BPd}(\mathrm{mmHg})$ & $79.40 \pm 7.92$ & & \\
\hline
\end{tabular}

24h ABPM 24h ambulatory blood pressure measurement, BPd diastolic blood pressure, BPs systolic blood pressure 
but not with bisoprolol resulted in a decrease in serum ADMA levels ${ }^{20}$. Compared to bisoprolol, nebivolol was shown to increase NO levels ${ }^{21}$. He et al. found significantly higher NOS activity in amlodipine treated patients compared to placebo ${ }^{22}$, however the results are inconsistent when compared with the results of Tzemos et al., who did show only improvement in endothelial function by treatment with valsartan, but did not show improvement in endothelial function after 16 weeks of treatment with amlodipine ${ }^{23}$.

In all the mentioned studies, increase in eNOS activity and/or NO plasmatic levels is generally considered beneficial for hypertensive patients; however, it is still not fully elucidated which drugs shall be used to reach this aim. In the specific situation in humans, i.e. in VEGFinhibitors induced hypertension, inhibition of eNOS by VEGF-inhibitors results in resistant hypertension and several case reports were described that NO supplementation using long acting nitric oxide donors resulted in BP normalization in affected individuals ${ }^{24}$. However, we found no change in NOx levels after initiation of antihypertensive therapy compared to pre-treatment values. A possible explanation is the small number of repeatedly measured hypertensive patients or the significant influence of genetics $(91 \%$ of these subjects had a positive family history of hypertension) or that the targets of action of used antihypertensive drugs (e.g. angiotensin converting enzyme, calcium channel and others) do not affect the overall ED or the level of individual endothelial substances.

We also determined the levels of NOx in 10 individuals with resistant hypertension and we also observed a trend for further decrease in plasmatic NOx levels. This probably reflects the persistance of ED also in the later phases of hypertension despite intensive anti-hypertensive treatment.

\section{Study strengths and limitations}

One of the biggest strengths of our study is the enrollment of a unique cohort of otherwise healthy hypertensive individuals, who did not present with a history of metabolic or cardiovascular disease, or taking drugs, non-smokers and non-alcoholics with the same dietary habits, thus avoiding the confounding factors potentially affecting NO levels. However, despite very strict exclusion and inclusion criteria that were set up to ensure maximal homogeneity of the study cohort, it is not possible to ensure full conformity in minor intersubject variables, including e.g. the genetic background (e.g. polymorphisms and mutations in NOS gene were not addressed) and their lifestyles. One limitation of study is absence of timing of blood sampling according to phase of menstrual cycle in females despite the well known effect of the menstrual cycle on NO production $^{25}$. A second limitation of the study is the small sample sizes due to the high economic cost of complex laboratory tests. For the same reasons, we were not able to rule out secondary hypertension using specific endocrinological laboratory tests, however, secondary hypertension was not suspected in any of the subjects according to the general features of secondary hypertension listed in the 2018 ESC / ESH Guidelines for the Management of Arterial Hypertension (e.g. hypokalemia etc) ( ref. $^{7}$ ).

\section{CONCLUSIONS}

In our study, we demonstrated significantly lower plasmatic NOx levels in patients with newly diagnosed hypertension, which were more profound in patients with resistant hypertension. On the contrary, plasmatic levels of other endothelial substances were not significantly different. We can thus hypothesize that changes in the plasmatic levels of NOx are one of the first changes in the pathophysiology of hypertension and that these persist into the later stages. Our results are consistent with the highly complex physiology of vascular tone regulation and confirms that NO is indeed the main endothelial vasodilator through which a large part of other endothelial agents act. These agents, although not significantly different in hypertensive patients themselves, act additively and probably reduce NOx levels together. Moreover, NOx levels are highly variable and are influenced by a large number of exogenous and endogenous factors even in normotensive individuals. Our results thus demonstrate, that ED cannot be assessed only by determining the plasmatic level of only one or a few endothelial substances and that a complex approach is needed in each hypertensive patient individually.

Acknowledgement: This research did not receive any specific grant from funding agencies in the public, commercial, or not-for-profit sectors.

Author contibutions: VB, JN: data collection; VB, JN, JS, MS: literature search; VB: manuscript writing; MT, JT: laboratory analysis; VR: data analysis; JS, MS: final approval.

Conflict of interest statement: The authors state that there are no conflicts of interest regarding the publication of this article.

\section{REFERENCES}

1. Williams B, Mancia G, Spiering W, Agabiti Rosei E, Azizi M, Burnier M, Clement DL, Coca A, de Simone G, Dominiczak A, Kahan T, Mahfoud F, Redon J, Ruilope L, Zanchetti A, Kerins M, Kjeldsen SE, Kreutz R, Laurent S, Lip GYH, McManus R, Narkiewicz K, Ruschitzka F, Schmieder RE, Shlyakhto E, Tsioufis C, Aboyans V, Desormais I; Authors/Task Force Members:. 2018 ESC/ESH. 2018 ESC/ESH Guidelines for the management of arterial hypertension: The Task Force for the management of arterial hypertension of the European Society of Cardiology and the European Society of Hypertension: The Task Force for the management of arterial hypertension of the European Society of Cardiology and the European Society of Hypertension. J Hypertens 2018;36(10):1953-2041.

2. Ettehad D, Emdin CA, Kiran A, Anderson SG, Callender T, Emberson J, Chalmers J, Rodgers A, Rahimi K. Blood pressure lowering for prevention of cardiovascular disease and death: a systematic review and meta-analysis. Lancet Lond Engl 2016;387(10022):957-67.

3. Weaver DJ. Hypertension in Children and Adolescents. Pediatr Rev 2017;38(8):369-82.

4. WHO | Raised blood pressure [Internet]. WHO. [cited 2017 Jul 3]. Available on: http://www.who.int/gho/ncd/risk_factors/blood_pressure_prevalence_text/en/ 
5. Konukoglu D, Uzun H. Endothelial Dysfunction and Hypertension. Adv Exp Med Biol 2017;956:511-40.

6. Biel V, Novak J, Pluhacek L, Spac J. Flow mediated dilation - její úloha a význam ve screeningu rizika kardiovaskulárních chorob. Interní Med 2019; 21(2): 92-96. (In Czech)

7. Williams B, Mancia G, Spiering W, Rosei EA, Azizi M, Burnier $M$, Clement DL, Coca A, de Simone G, Dominiczak A, Kahan T, Mahfoud F, Redon J, Ruilope L, Zanchetti A, Kerins M, Kjeldsen SE, Kreutz R, Laurent S, Lip GYH, McManus R, Narkiewicz K, Ruschitzka F, Schmieder RE, Shlyakhto E, Tsioufis C, Aboyans V, Desormais I, ESC Scientific Document Group 2018 ESC/ESH Guidelines for the management of arterial hypertension Eur Heart J 2018;33:3021-104.

8. Alrefai AA, Habib D, Yassen Rl, Gabr MK, Habeeb RM. Association of endothelial nitric oxide synthase (eNOS) gene G894T polymorphism with hypertension risk and complications. Mol Cell Biochem 2016;421(1-2):103-10.

9. Jasperse JL, Laughlin MH. Endothelial function and exercise training: evidence from studies using animal models. Med Sci Sports Exerc 2006;38(3):445-54

10. Shek EW, Brands MW, Hall JE. Chronic leptin infusion increases arterial pressure. Hypertens Dallas Tex 19791998 (1 Pt 2):409-14.

11. Su Y, Han W, Giraldo C, De Li Y, Blockr ER. Effect of cigarette smoke extract on nitric oxide synthase in pulmonary artery endothelial cells. Am J Respir Cell Mol Biol 1998;19(5):819-25.

12. Walther C, Gielsen $S$, Hambrecht R. The effect of exercise training on endothelial function in cardiovascular disease in humans. Exerc Sport Sci Rev 2004;32(4):129-34.

13. Vogel RA, Corretti MC, Plotnick GD. Effect of a single high-fat meal on endothelial function in healthy subjects. Am J Cardio 1997;79(3):350-4.

14. Lundberg JO, Carlström M, Larsen FJ, Weitzberg E. Roles of dietary inorganic nitrate in cardiovascular health and disease. Cardiovasc Res 2011;89(3):525-32.

15. Vasdev S, Gill V. The antihypertensive effect of arginine. Int J Angiol 2008;17(1):7-22.
16. Lin HY, Lee YT, Chan YW, Tse G. Animal models for the study of primary and secondary hypertension in humans. Biomed Rep 2016;5(6):653-9.

17. Node K, Kitakaze M, Yoshikawa H, Kosaka H, Hori M. Reduced plasma concentrations of nitrogen oxide in individuals with essential hypertension. Hypertension 1997;30:405-8.

18. Perticone F, Sciacqua A, Maio R, Perticone M, Galiano Leone G, Bruni R, Di Cello S, Pascale A, Talarico G, Greco L, Andreozzi F, Sesti G. Endothelial dysfunction, ADMA and insulin resistance in essential hypertension. Int J Cardiol 2010;142(3):236-41.

19. Ceconi C, Fox KM, Remme WJ, Simoons ML, Bertrand M, Parrinello G, Kluft C, Blann A, Cokkinos D, Ferrari R; EUROPA Investigators; PERTINENT Investigators and the Statistical Committee. ACE inhibition with perindopril and endothelial function. Results of a substudy of the EUROPA study: PERTINENT. Cardiovasc Res 2007;73(1):237-46.

20. Ito A, Egashira K, Narishige T, Muramatsu K, Takeshita A. Reninangiotensin system is involved in the mechanism of increased serum asymmetric dimethylarginine in essential hypertension. Jpn Circ J 2001;65(9):775-8.

21. Aladag MA, Turkoz Y, Parlakpinar H, Gul M. Nebivolol attenuates cerebral vasospasm both by increasing endothelial nitric oxide and by decreasing oxidative stress in an experimental subarachnoid haemorrhage. Br J Neurosurg 2017;31(4):439-45.

22. He Y, Si D, Yang C, Ni L, Li B, Ding M, Yang P. The effects of amlodipine and $\mathrm{S}(-)$-amlodipine on vascular endothelial function in patients with hypertension. Am J Hypertens 2014;27(1):27-31.

23. Tzemos N, Lim PO, Macdonald TM. Valsartan Improves Endothelial Dysfunction in Hypertension: A Randomized, Double-Blind Study. Cardiovasc Ther 2009;27(3):151-8.

24. Kruzliak P, Kovacova G, Pechanova O. Therapeutic potential of nitric oxide donors in the prevention and treatment of angiogenesisinhibitor-induced hypertension. Angiogenesis 2013;16(2):289-95.

25. Rosselli, M, Imthurm B, Macas E, Keller PJ, Dubey RK, Circulating Nitrite/Nitrate Levels Increase with Follicular Development: Indirect Evidence for Estradiol-Mediated NO Release. Biochem Biophys Res Commun 1994;202(3):1543-52. doi: 10.1006/bbrc.1994.2107 